
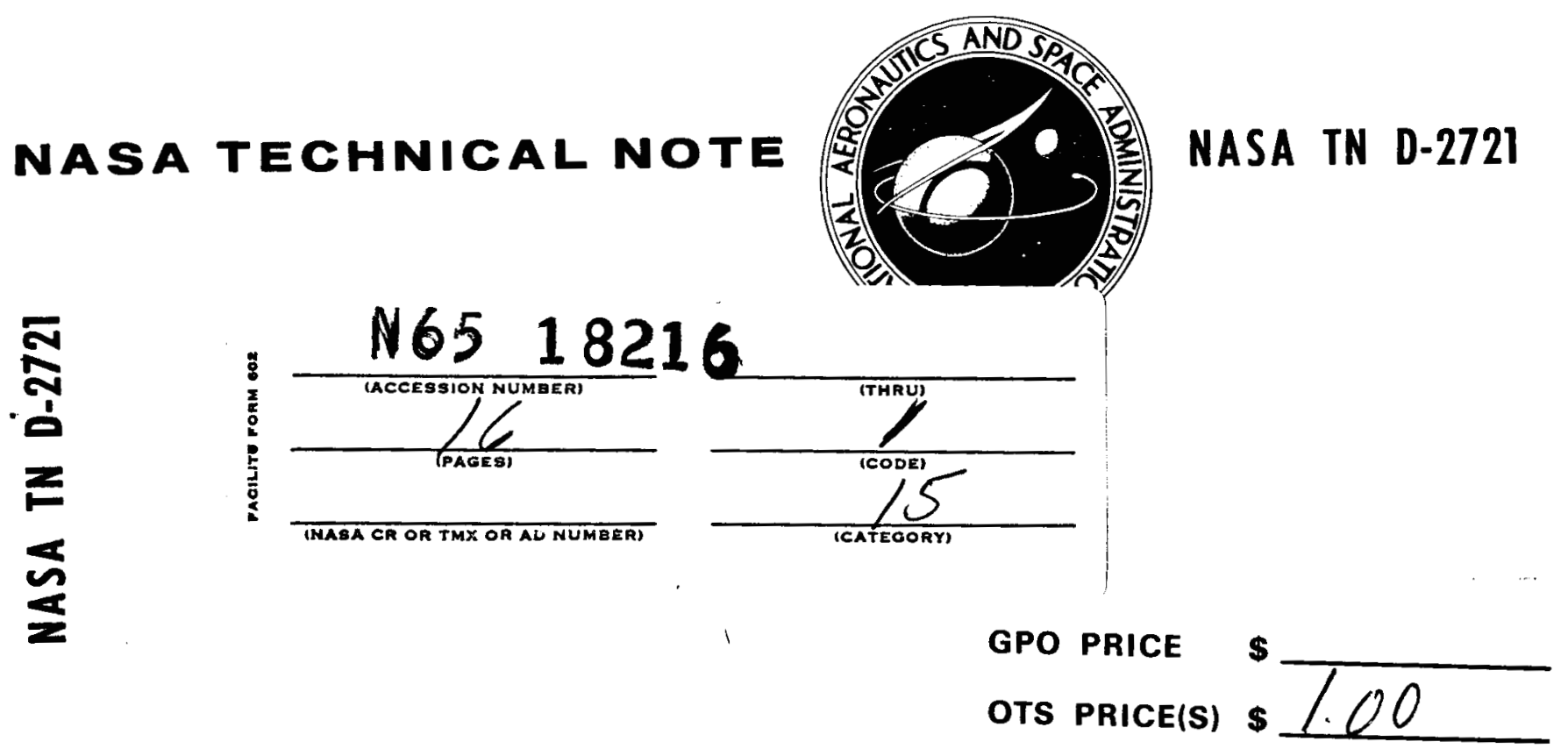

Hard copy $(\mathrm{HC})$

Microfiche (MF)

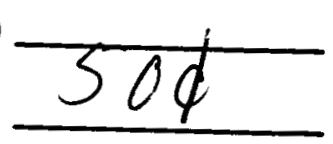

\title{
FRICTION AND WEAR OF
}

LOW-MELTING BINARY AND

TERNARY GALLIUM ALLOY FILMS

IN ARGON AND IN VACUUM

by Thomas J. Kuczkowski and Donald H. Buckley

Lewis Research Center

Cleveland, Obio

NATIONAL AERONAUTICS AND SPACE ADMINISTRATION - WASHINGTON, D. C. - MARCH 1965 
GALLIUM ALLOY FILMS IN ARGON AND IN VACUUM

By Thomas J. Kuczkowski and Donald H. Buckley

Lewis Research Center

Cleveland, Ohio 


\title{
FRICTION AND WEAR OF LOW-MELTING BINARY AND TERNARY
}

\author{
GALLIUM ALLOY FILMS IN ARGON AND IN VACUUM \\ by Thomas J. Kuczkowski and Donald H. Buckley \\ Lewis Research Center
}

SUMMARY

18216

Friction and wear experiments were conducted with thin lubricating films (approximately $0.001 \mathrm{in.} \mathrm{thick)} \mathrm{of} \mathrm{gallium} \mathrm{and} \mathrm{low-melting} \mathrm{binary} \mathrm{and} \mathrm{ternary} \mathrm{gallium} \mathrm{alloys} \mathrm{on}$ 440-C stainless steel and nickel surfaces. Experiments were conducted in argon and in vacuum environments. Binary alloy systems of gallium with indium, tin, and silver were examined. As a result of the friction and wear data obtained with the binary gallium alloys, a ternary alloy of gallium-indium-tin was examined as a lubricating film. Friction and wear experiments were conducted with a hemispherically tipped rider (3/16-in. rad.) sliding on a flat disk surface. The load on the rider was 1000 grams. Experiments in argon were conducted at sliding velocities of 5 to 2000 feet per minute. Both disk and rider specimens were of the same material. The gallium films were applied to the disk surface.

Results of this investigation indicate that the addition of other soft metals to gallium films appreciably reduced corrosive wear normally encountered with gallium. Surface films provided low friction and wear with a number of gallium alloy compositions. A ternary system of 20 weight percent gallium - 20 weight percent indium - 60 weight percent tin was effective in reducing friction and wear for 440-C stainless steel in vacuum $\left(10^{-11} \mathrm{~mm} \mathrm{Hg}\right)$. Rider wear rate was reduced to one ten-thousandth of that obtained with the unlubricated $440-\mathrm{C}$ stainless steel.

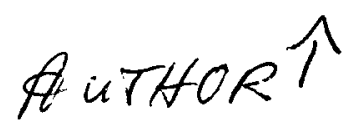

\section{INTRODUCTION}

The proper design of space lubrication systems requires that consideration be given to the lubricant as well as to the metals and alloys of which these systems are constructed. A lubricant for use in space is needed that will minimize friction and wear as do more conventional lubricants used in the Earth's atmosphere. The property of 
fluidity (which implies low shear strength) is highly desirable in a lubricating film. Further, an essential characteristic of a space lubricant is low vapor pressure.

The work of reference 1 shows the metal gallium to have the properties discussed in the previous paragraph. Pure gallium melts at $86^{\circ} \mathrm{F}$ and boils at $4360^{\circ} \mathrm{F}$ (ref. 2). At a temperature of $705^{\circ} \mathrm{F}$, its vapor pressure is $10^{-10}$ millimeter of mercury (ref. 3).

Associated with these very desirable properties, however, is an undesirable characteristic. Gallium is extremely corrosive and forms alloys with most common bearing materials. Reference 4 states that "Gallium is more aggressive in its attack on most solid metals at a given temperature than any other molten metal that has been tested." Gallium can be contained at temperatures to $1100^{\circ} \mathrm{F}$ only by a few materials: some of the refractory oxides, quartz, graphite, and the metals tungsten and tantalum. At higher temperatures, however, these materials lose some of their effectiveness in re-

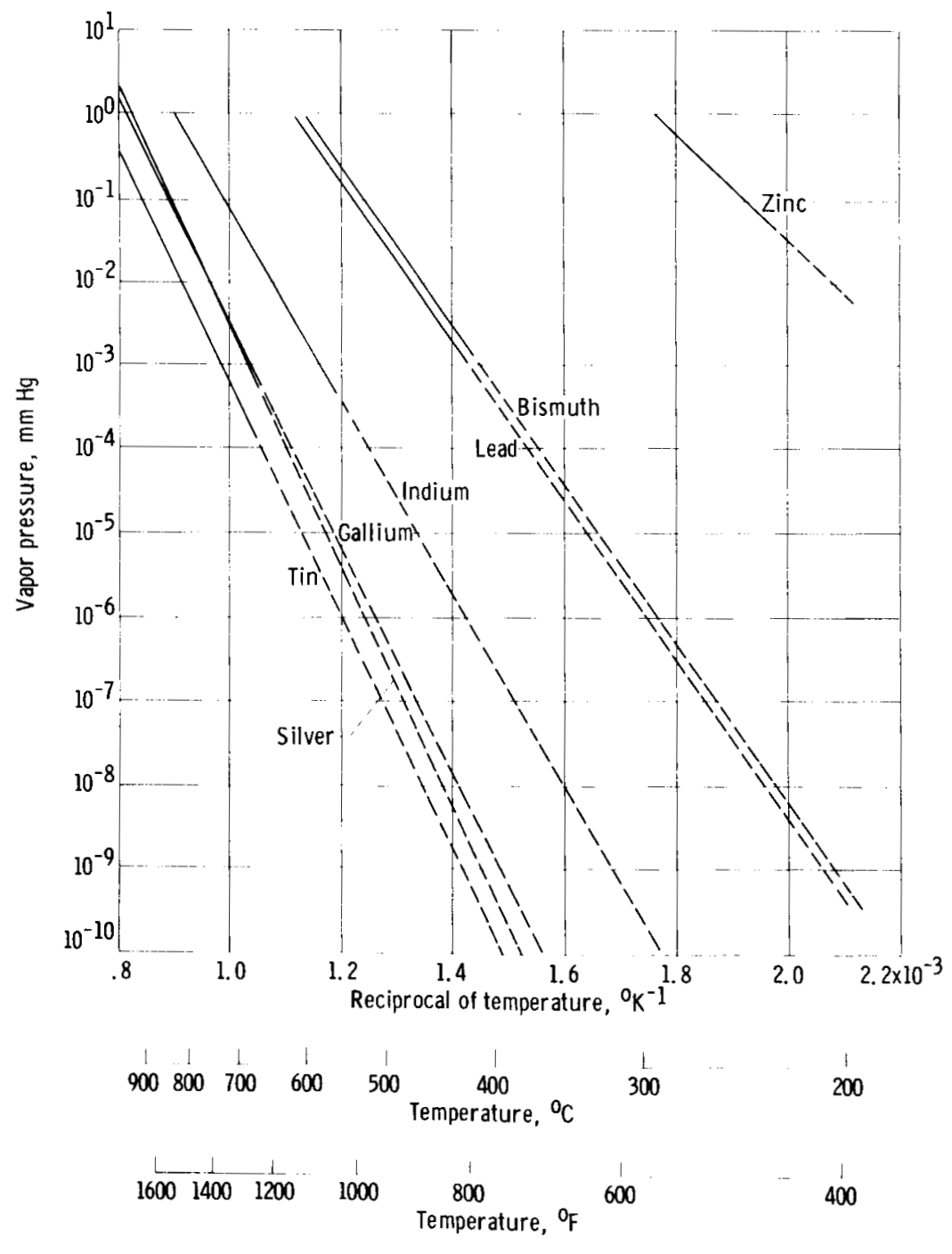

Figure 1. - Vapor pressure of low-melting pure metals as function of temperature (data from ref. 3 ). 


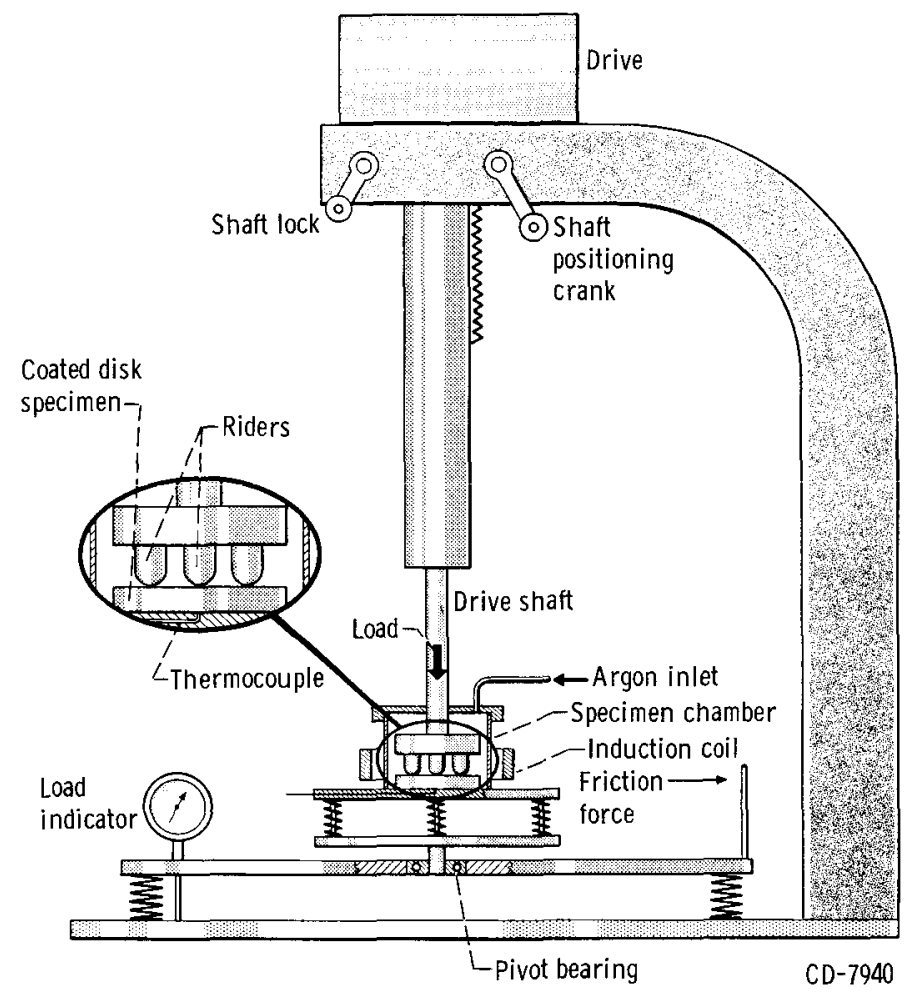

Figure 2. - High-temperature friction apparatus. Argon atmosphere flow, 6 feet per minute. sisting the attack of liquid gallium.

The apparent undesirable characteristic of surface interaction can be utilized to advantage when lubricating with gallium. Because it alloys with most common metals, gallium may be alloyed sufficiently to reduce its concentration and thereby to reduce corrosion. In order to maintain the alloy as a fluid at room temperature, it would be desirable to alloy gallium with lowmelting-point metals. Some of these metals and the temperature required to yield a vapor pressure of $10^{-10}$ millimeter of mercury are shown in figure 1. As figure 1 suggests, there are three metals other than gallium that exhibit a vapor pressure of $10^{-10}$ millimeter of mercury in the same temperature range as gallium. These

metals, tin, silver, and indium, were therefore chosen for alloying with gallium.

This investigation was conducted to evaluate the friction and wear characteristics in an inert environment (argon or vacuum) of binary or ternary systems so chosen as to reduce corrosive wear:

(1) Four binary alloy systems, gallium-tin, gallium-silver, gallium-indium, and indium-tin (in argon)

(2) Various alloys of the ternary system gallium-indium-tin (in argon)

(3) The most promising alloy coatings of steps 1 and 2 (in ultrahigh vacuum to $10^{-11}$ $\mathrm{mm} \mathrm{Hg)}$

Friction and wear experiments were conducted with a hemispherically tipped, 3/16inch-radius rider on a flat disk specimen under a load of 1000 grams. The speeds investigated were 6 feet per minute in argon and a range of from 5 to 2000 feet per minute in ultrahigh vacuum. In all except six runs (which are noted in the text), both the disk and rider were 440-C stainless steel.

\section{APPARATUS}

The apparatus used in the screening portion of this investigation (the runs made in 
argon at slow speed) was a high-temperature friction apparatus, a detailed description of which is given in reference 5 . Figure 2 shows the essential details of the apparatus. The specimens are surrounded by an induction heating coil in the chamber. The disk is restrained from rotating by a strain-gage linkage from which friction force is obtained. Three riders (3/16-in. - rad. hemisphere) are mounted in the rotating head of the apparatus, as shown in the diagram, and leveled with a dial indicator. The precalibrated load is applied by lowering the rotating head to compress the supporting springs to a predeter mined point on the load indicator. This compression corresponds to a load of 3000 grams on the springs or 1000 grams per rider. The chamber is capped and a flow of argon is initiated to exclude oxygen from the chamber.

The vacuum friction apparatus used in the vacuum portion of this investigation is shown in figure 3. The apparatus is separated into two distinct chambers: (1) the specimen chamber and (2) the bearing chamber.

The rough pumping system of the apparatus consists of a cold trap, which is made up of molecular sieves backed by liquid-nitrogen-cooled containers. This system is connected to the mechanical pumps through a 2 -inch stainless-steel vacuum valve. The mechanical pumps consist of a lobe blower pump backed by a standard mechanical pump. The system has connections to each of the two chambers.

The bearing chamber is connected to the low-vacuum chamber through a 2 -inch valve. The chamber is equipped with a 125-liter-per-second ion pump, which is placed in operation only after the mechanical pumping system has reduced the chamber pressure to the $10^{-4}$-millimeter-of-mercury range. The bearing chamber is also equipped with a liquid-nitrogen-cooled titanium sublimation pump. This unit is used to pump the bearing chamber into the $10^{-10}$-millimeter-of-mercury range in preparation for an experiment.

The specimen chamber is connected to the mechanical pumping system through a bakable high-vacuum valve. The specimen chamber is equipped with a 400-liter-persecond ion pump, as well as with liquid-nitrogen and liquid-helium cryopumping surfaces.

The rotating shaft upon which the disk specimen is mounted is supported on bearings in the bearing chamber. The shaft projects through the rear wall of the test chamber by means of a molecular flow seal. On the end of the shaft in the bearing chamber is mounted a 20-pole magnet, which is separated from a similar magnet driven outside the vacuum chamber by a 0.030-inch diaphragm (0.150-in. air gap). The driven magnet is powered by a hydraulic motor with a variable speed capability to $4000 \mathrm{rpm}$ (sliding velocity, $2000 \mathrm{ft} / \mathrm{min}$ ). Because of instabilities in the drive motor at low speeds $(10,20$, and $100 \mathrm{rpm})$, these speeds were obtained by utilizing a speed reducer with a ratio of 10 .

The shaft support bearings have a large clearance. These bearings are so mounted 

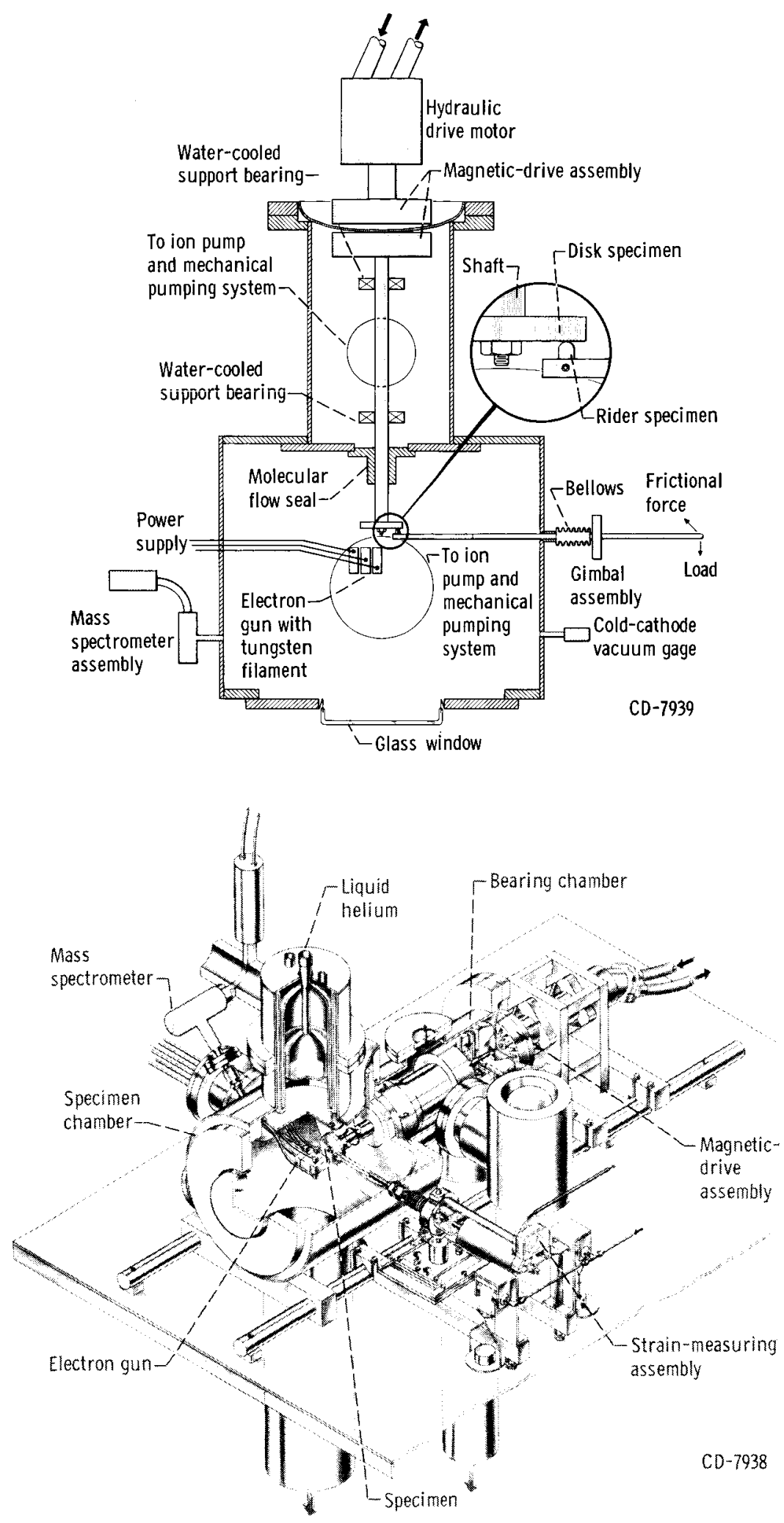

Figure 3. - Ultra-high-vacuum friction apparatus. 
in a cartridge that the shaft expands into the test chamber, and the possibility of the magnet striking the diaphragm is eliminated. Since loading was applied by dead weights, this expansion did not change the load on the specimens. The bearing cartridge is watercooled to prevent damaging the bearings during the bakeout cycle.

On the end of the horizontal shaft in the test chamber is mounted the disk specimen. Against the disk, a bullet-tipped (3/16-in. hemisphere) rider specimen is loaded. The rider is held in a rigid arm, which projects through a port in the side of the vacuum chamber. The seal (0.030-in. gold O-rings) is made at the wall by utilizing a bellows connection between the chamber wall and the rigid arm supporting the rider. To the rigid arm outside the vacuum chamber is fastened a removable gimbal assembly, which is used to load the rider against the disk surface and also to monitor the frictional force through a strain-gage assembly.

The chamber is equipped with a cold-cathode vacuum gage for measuring pressures. A partial pressure analyzer is used to determine the gaseous molecular constituents of the chamber and to indicate the total pressure (summation of partial pressures). An electron gun is placed in position in the chamber to clean the surface of the disk specimen. The power used for cleaning was 300 watts at 30,000 volts.

\section{RESULTS AND DISCUSSION}

\section{Experiments in Argon}

The gallium-tin phase diagram (fig. 4(a)) was obtained from reference 6. Also presented in figure $4(\mathrm{a})$ is the effect of various alloy concentrations on the friction and wear of gallium-tin coated 440-C stainless steel at room temperature and at $500^{\circ} \mathrm{F}$. The figure shows that the effect of increasing the tin content on friction is not appreciable. The maximum friction coefficient occurred at the eutectic composition.

The wear data, however, differ markedly. There is a slight decrease in wear with increasing tin content at room temperature. At $500^{\circ} \mathrm{F}$, the wear rates for the first three high-gallium concentrations, namely, 100, 96, and 92 percent gallium, were $2 \frac{1}{2}$ to 5 times as great as the wear rates for the same alloys at room temperature. The alloys with greater percentages of tin had wear rates at $500^{\circ} \mathrm{F}$ comparable with those obtained in the room-temperature experiments.

Difficulty was encountered in coating a disk with pure tin. The tin did not wet the disk specimen and for this reason no data are presented for 100 percent tin. Somewhat the same problem was encountered with the 80 percent tin alloy, but the 20 percent gallium content seemed to act as a flux for this alloy.

The phase diagram for gallium-silver (ref. 6) is shown in figure 4(b) together with 

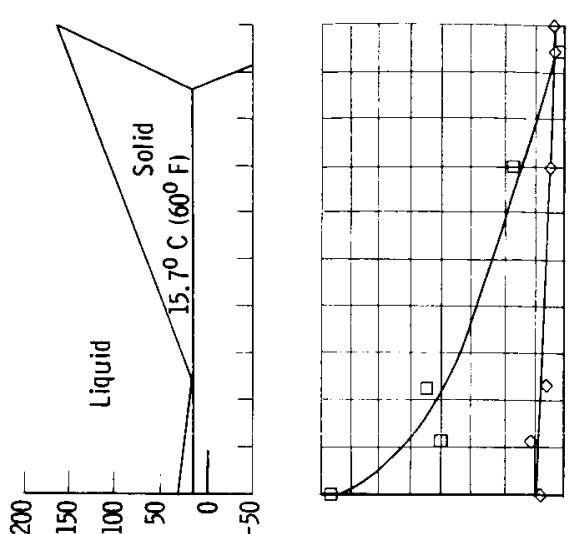

$\partial_{0}$ 'adnұedadua!

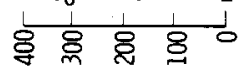

$t_{0}$ 'วגп⿺е дәdша।

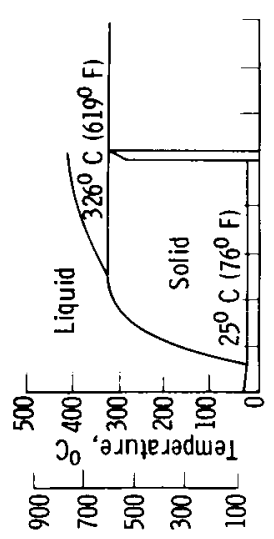

$t_{0}$ 'axnfe גadua1
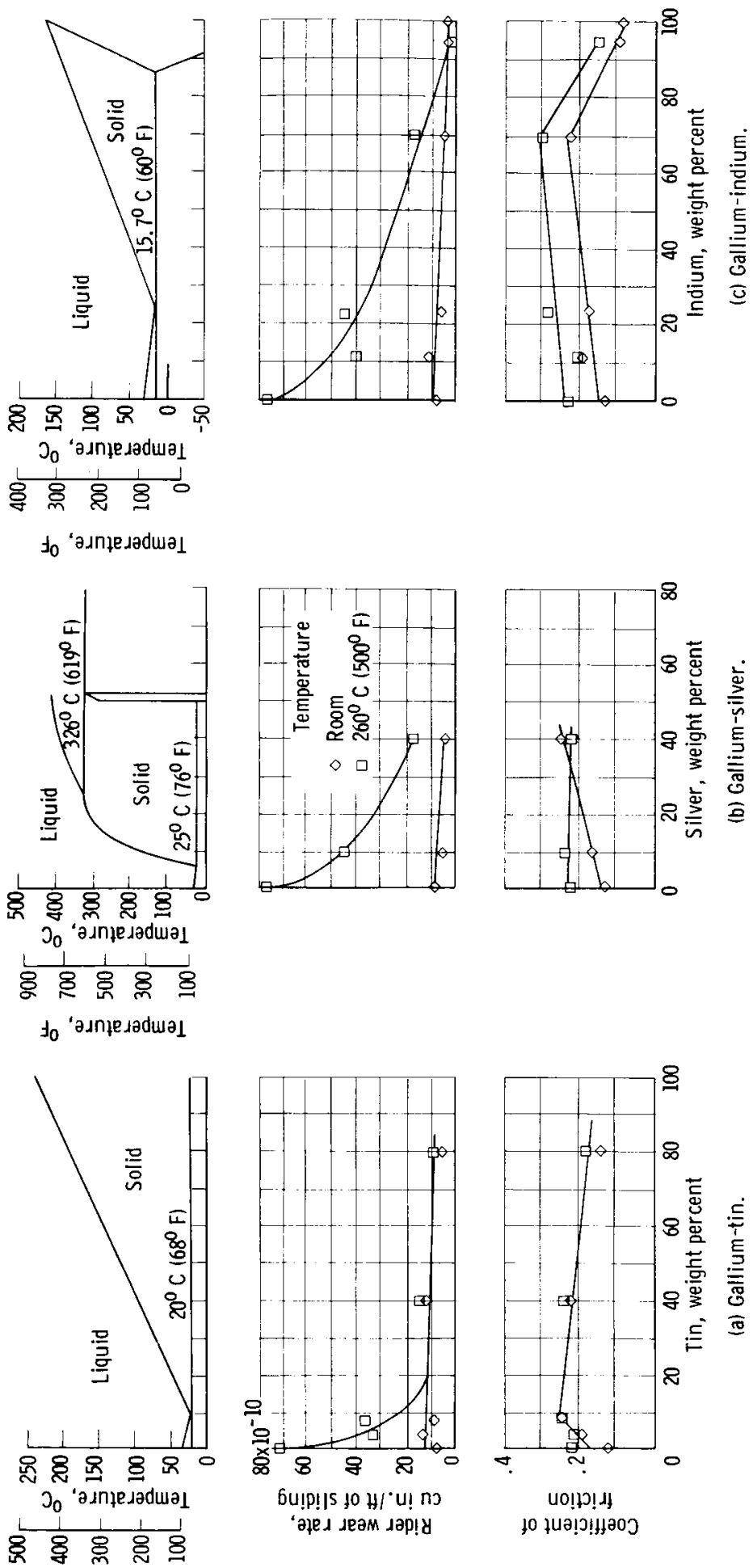

i

8

음

든

岕

高

is

额

它

高.

믈

동

흔 는

등 ํㅡㄹ

드ㅇㅗㅗ

듕

苋

동

음

言号

용

동

몬으

苋苞

흘.들

过

兽

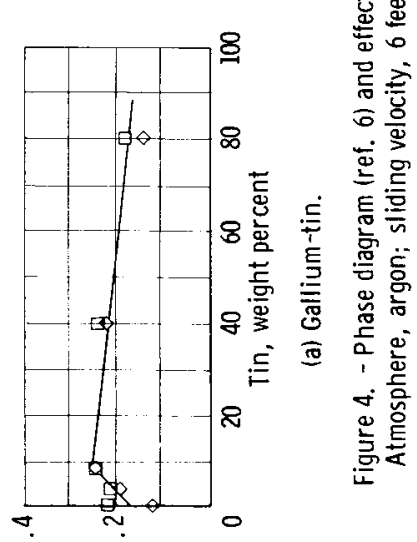

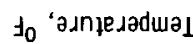


the friction and wear values of the various gallium-silver alloys. The effect of increasing silver content on the friction is similar to that for the gallium-tin system (i. e., not appreciable). At room temperature, the friction increases from 0.13 for pure gallium to 0.23 for 40 percent silver. At $500^{\circ} \mathrm{F}$, the difference is much less, 0.22 to 0.25 over the same composition range.

It is again the wear that exhibits the major effect. At room temperature, a slight decrease occurs in wear over the composition range of 0 to 40 percent silver. The ratios of wear at $500^{\circ} \mathrm{F}$ to that at room temperature are 10 for pure gallium, 6 for 10 percent silver alloy coating, and only 4 for a 40 percent alloy coating.

Any alloys beyond 40 percent silver were not tested because the next logical concentration would have contained no free gallium phase and would have had a high melting point.

The phase diagram for gallium-indium is presented in figure $4(\mathrm{c})$ as obtained from reference 6 . Figure 4(c) also shows the effect of various gallium-indium alloy concentrations on wear and friction. Again the effect of alloy concentration on friction was limited at both temperatures investigated. The maximum friction coefficient was obtained with the 71 percent indium alloy.

The wear values obtained are consistent with the results obtained with the galliumtin and gallium-silver systems. At room temperature, a slight decrease is noted in the wear as the concentration of indium is increased. The wear decreases by about one-half from pure gallium to pure indium. At $500^{\circ} \mathrm{F}$, the wear decreased by a factor of 12 with the addition of $\mathbf{5}$ percent indium to gallium.

The wear mechanism operating in the three gallium binary systems is believed to be as follows: The decrease in wear for all bearing alloy systems with increasing content of the alloying element is attributed to two factors. First, the concentration of gallium, the corrosive constituent of the alloy, is reduced as the concentration of alloying element is increased. Second, the alloying elements tin, silver, and indium are low-shearstrength materials that will keep the friction and wear to a minimum.

The drop in friction at the high percentages of indium in figure $4(\mathrm{c})$ is attributed to the extended solubility of gallium in indium. Reference 6 states that 12 weight percent gallium is soluble in indium at room temperature; therefore, any alloy containing 12 or more percent gallium will exhibit the properties of the saturated solid solution, namely, a higher shear strength. The 95-percent- and 100-percent-indium alloys as a consequence have a lower shear strength and, in turn, exhibit lower friction.

A ternary system was next considered for investigation. The melting point of silver is high, and a ternary system containing it would be expected to have high shear strength. For this reason, silver was dropped from any further investigation. The only ternary system considered therefore was that of gallium-indium-tin. Before this system was investigated, however, alloys of the indium-tin system were investigated since it is the 
only combination (of the elements considered for a ternary system) on which data were not available.

The indium-tin phase diagram obtained from reference 6 is presented in figure 5 along with the wear and friction curves of the alloy. The experiments were performed only at $500^{\circ} \mathrm{F}$ because the wear data of figure 4 showed that this temperature gave the most meaningful results. The results indicate both increasing wear and friction with increasing tin content. The concentrations investigated stop with 50 percent tin because of the difficulty experienced in coating disks with high-tin alloys.

The compositions of the various ternary systems by weight percent are as shown

\begin{tabular}{|c|c|c|}
\hline Gallium & Indium & Tin \\
\hline 76 & 15 & 9 \\
65 & 12.5 & 22.5 \\
50 & 28 & 22 \\
33 & 50 & 17 \\
20 & 40 & 40 \\
20 & 60 & 20 \\
\hline
\end{tabular}
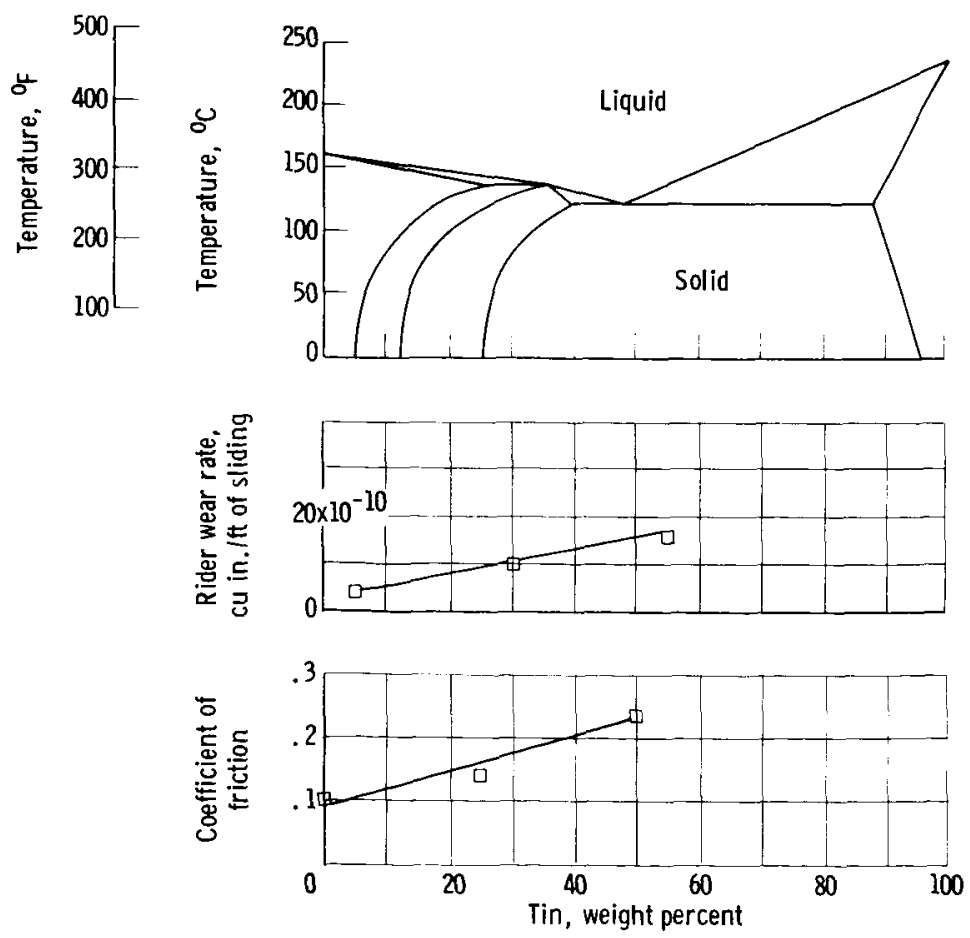

Figure 5. - Indium-tin phase diagram (ref. 6) and effect of coating-alloy concentration on friction and wear of 440-C stainless steel sliding on 440-C. Atmosphere, argon; temperature, $260^{\circ} \mathrm{C}\left(500^{\circ} \mathrm{F}\right)$; sliding velocity, 6 feet per minute; run time, 1 hour; surface film initially approximately 0.001 inch thick. in the table at the left.

The friction and wear characteristics of these alloys are presented in figure 6 along with the data obtained from two gallium experiments and an uncoated $440-\mathrm{C}$ experiment for comparison. As stated in an earlier section, there is little effect of coating composition on friction. The friction at $500^{\circ} \mathrm{F}$ of pure gallium and the first four high-gallium coatings $(76,65,50$, and 33 percent gallium) exhibited a friction coefficient in the range, $0.22 \pm 0.02$. Only for the lowest gallium concentrations (20 percent gallium), did the friction decrease. The coating 20 gallium - 40 indium 40 tin had a friction coefficient of 0.16 , and the coating 20 gallium 60 indium - 20 tin had a friction coefficient of 0.12 .

The wear again exhibited the most pronounced effect of the alloy coating concentration (fig. 6). The 100 -percent-gallium and the 76 percent-gallium alloys exhibited wear about 25 times as much as the best alloy tested, 20 gallium - 


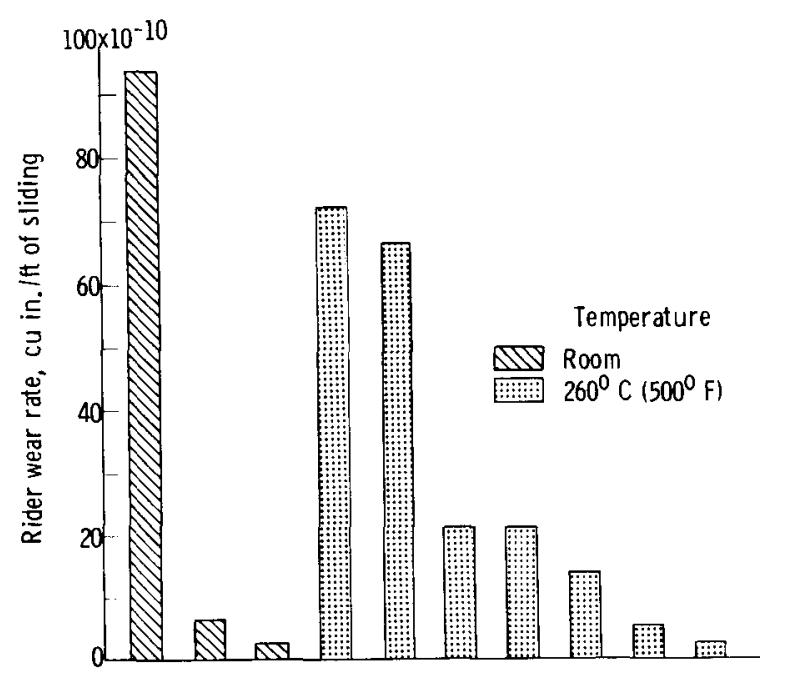

60 indium - 20 tin. The 65 -percent- and 50percent-gallium alloys showed wear values only one-third of the high-gallium alloys. The last three gallium alloys $(33 \mathrm{Ga}-$ $50 \mathrm{In}-17 \mathrm{Sn}, 20 \mathrm{Ga}-40 \mathrm{In}-40 \mathrm{Sn}$, and $20 \mathrm{Ga}-60 \mathrm{In}-20 \mathrm{Sn}$ ) showed a decrease in both wear and friction with less gallium. The 20-gallium - 60-indium - 20-tin coating was also run at room temperature, and no difference was observed in either friction or wear from the $500^{\circ} \mathrm{F}$ data.

\section{Experiments in Vacuum}

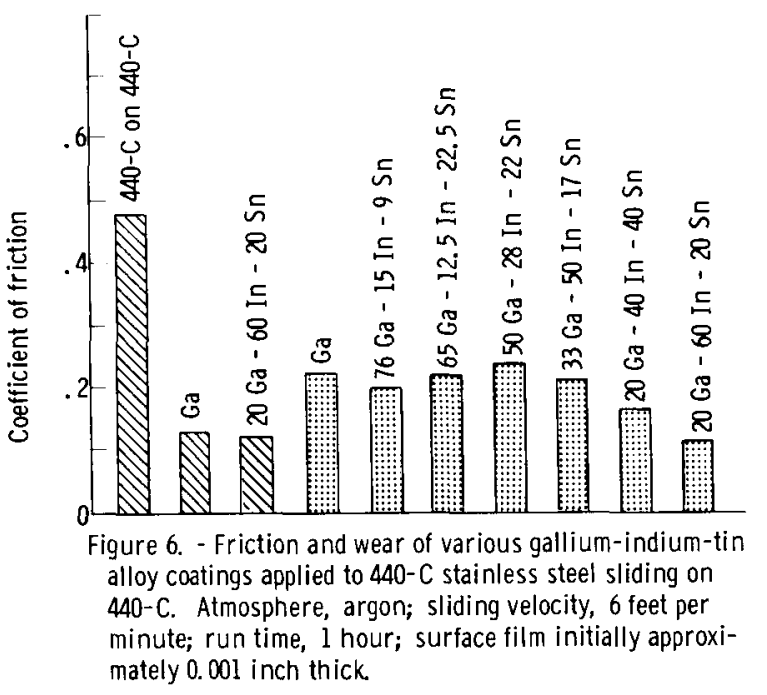

Experiments were conducted in vacuum at ambient pressures to $10^{-11}$ millimeter of mercury. The results of these experiments are presented in figure 7 and table I. All the specimens were subjected to bakeout at $700^{\circ} \mathrm{F}$ for approximately 20 hours and cleaning with the electron gun previously described. Because of the time required to make a run (5 days), only the most promising alloy coatings were examined in vacuum. Each experiment was made under the same conditions. Experimental points were obtained at 5, 10, 50, 200,400,800, 1200, 1600, and 2000 feet per minute. Each run was for 12 minutes.

The binary gallium-tin alloys gave the lowest friction of any coating at the low speeds, but their effectiveness was short lived. The wear per foot of sliding (table I) indicates that these binary coatings are subject to high wear compared with the ternary coatings. Their wear is comparable to that with pure gallium.

The most promising alloy examined was the 20-gallium - 60-indium - 20-tin coating. This alloy exhibited high friction at low speeds but decreased steadily to a value of 0.18 at speeds of 1600 and 2000 feet per minute. In each of the two experiments with this alloy, the coating did not fail. Both experiments were terminated because of time. This alloy could have conceivably run to higher speeds and for a longer time. The most impressive characteristic of this alloy is that the wear was reduced by an order of magnitude over any alloy coating examined and by four orders of magnitude over the uncoated 


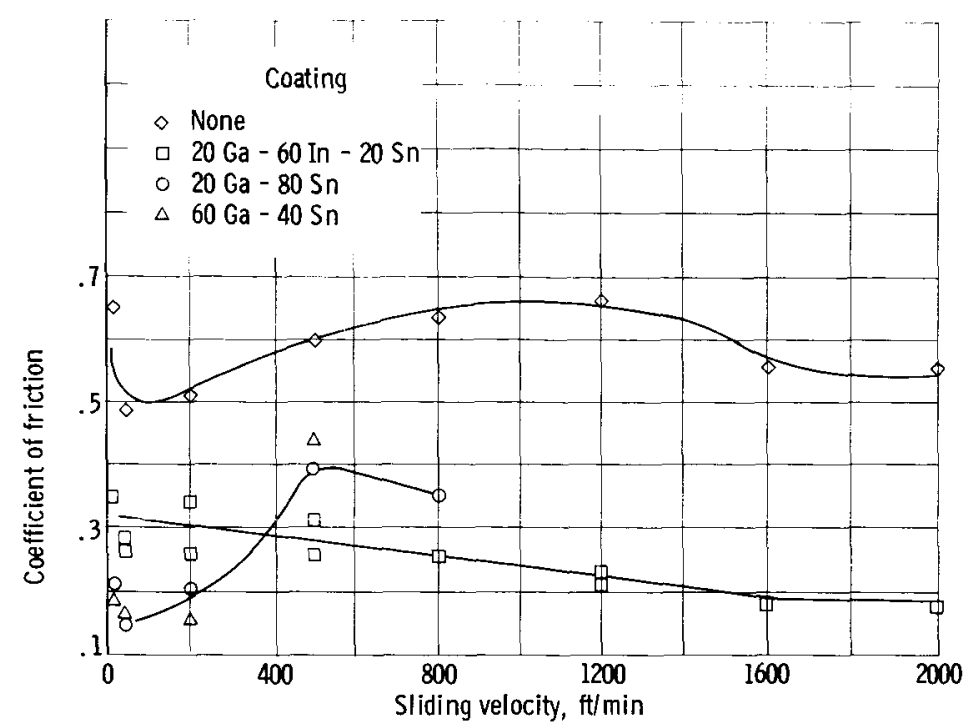

Figure 7. - Effect of sliding velocity and coating alloy on friction and wear of $440-C$ stainless steel sliding on $440-C$ in vacuum $\left(10^{-11} \mathrm{~mm} \mathrm{Hg}\right)$. Load, 1000 grams; run time, 12 minutes per point; surface film initially approximately 0.001 inch thick; no external specimen heating.

TABLE I. - WEAR FOR 440-C STAINLESS

STEEL RIDERS SLIDING ON 440-C DISKS

IN VACUUM $\left(10^{-11} \mathrm{~mm} \mathrm{Hg}\right)$

[Load, $1000 \mathrm{~g}$; ambient temperature; sliding velocity, 5 to $2000 \mathrm{ft} / \mathrm{min}$; total run time, $108 \mathrm{~min}$.]

\begin{tabular}{|c|c|}
\hline Coating & $\begin{array}{l}\text { Average wear rate, } \\
\text { cu in. / } \mathrm{ft} \text { of sliding }\end{array}$ \\
\hline None & $264.200 \times 10^{-10}$ \\
\hline $20 \mathrm{Ga}-60 \mathrm{In}-20 \mathrm{Sn}$ & .028 \\
\hline 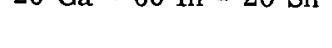 & .049 \\
\hline $60 \mathrm{Ga}-40 \mathrm{Sn}$ & .656 \\
\hline $20 \mathrm{Ga}-80 \mathrm{Sn}$ & .401 \\
\hline Ga (oxidized) & .534 \\
\hline Ga (vacuum coated) & .570 \\
\hline
\end{tabular}

disk and rider combination (table I).

Figure 8 presents surface profile traces and macrophotographs of the ternary coated and uncoated disks. The metal transferred to the disk (fig. 8) of the uncoated 440-C specimens can readily be seen. In contrast, the disk used with the ternary alloy shows no metal transfer (fig. 8); the rider showed very little wear.

Stainless steel has been shown (ref. 4) to be resistant to the attack of gallium at room temperature. Stainless steel, however, may not be the only metal considered for lubrication systems; for example, metals such as nickel-base alloys that are less resistant to gallium attack may be considered. Therefore, it was decided to study the effects of gallium-indium alloys on the friction and particularly wear of a metal less resistant to attack by gallium, namely, nickel. Nickel reacts readily with gallium and tends to alloy with the gallium of the coating material.

The results of friction and wear experiments with nickel in vacuum are shown in figure 9 . In 


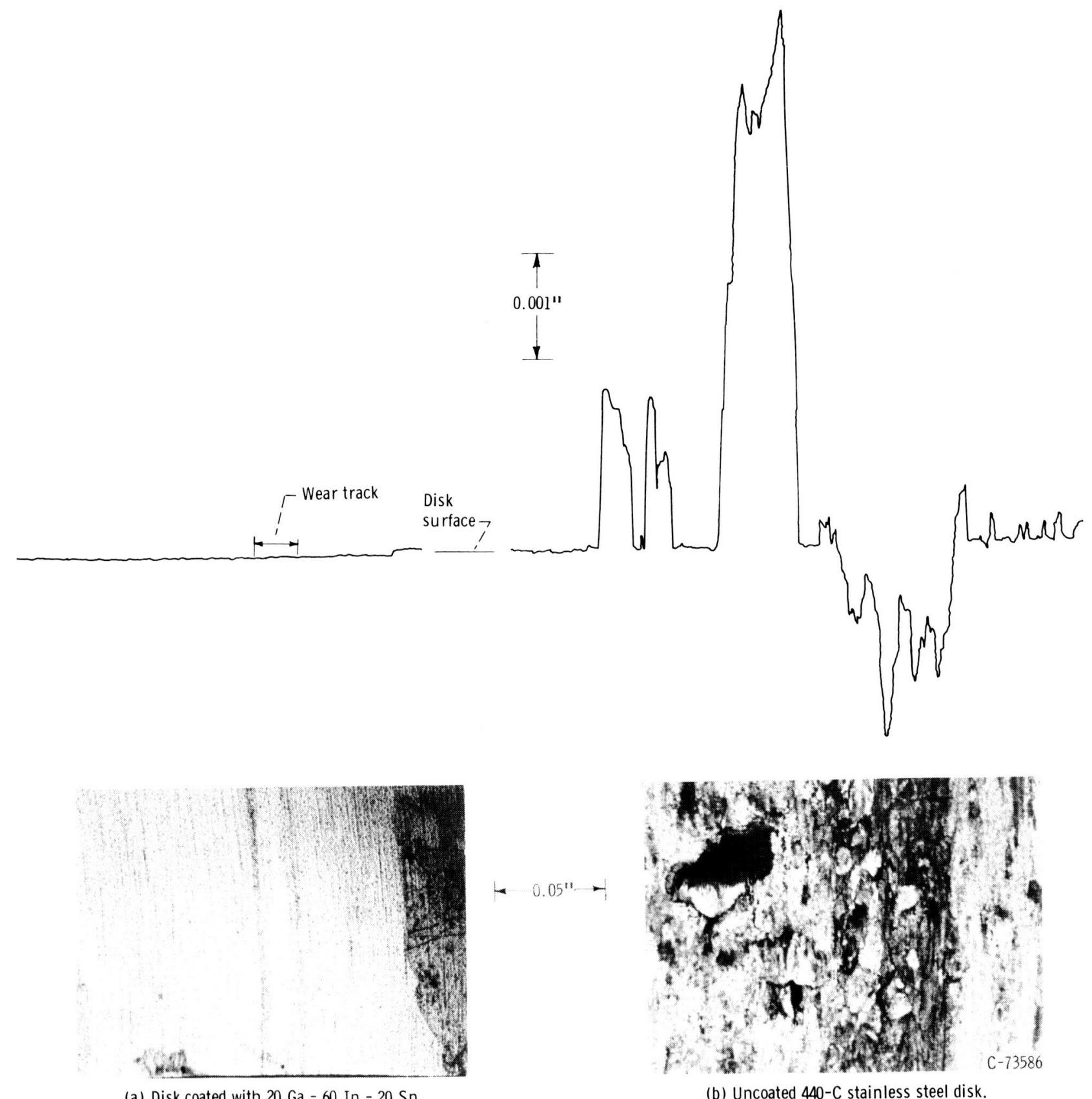

(a) Disk coated with $20 \mathrm{Ga}-60 \mathrm{In}-20 \mathrm{Sn}$.

(b) Uncoated $440-\mathrm{C}$ stainless steel disk.

Figure 8. - Surface profile tracings and macrophotographs of uncoated and coated 440-C stainless steel disks. 

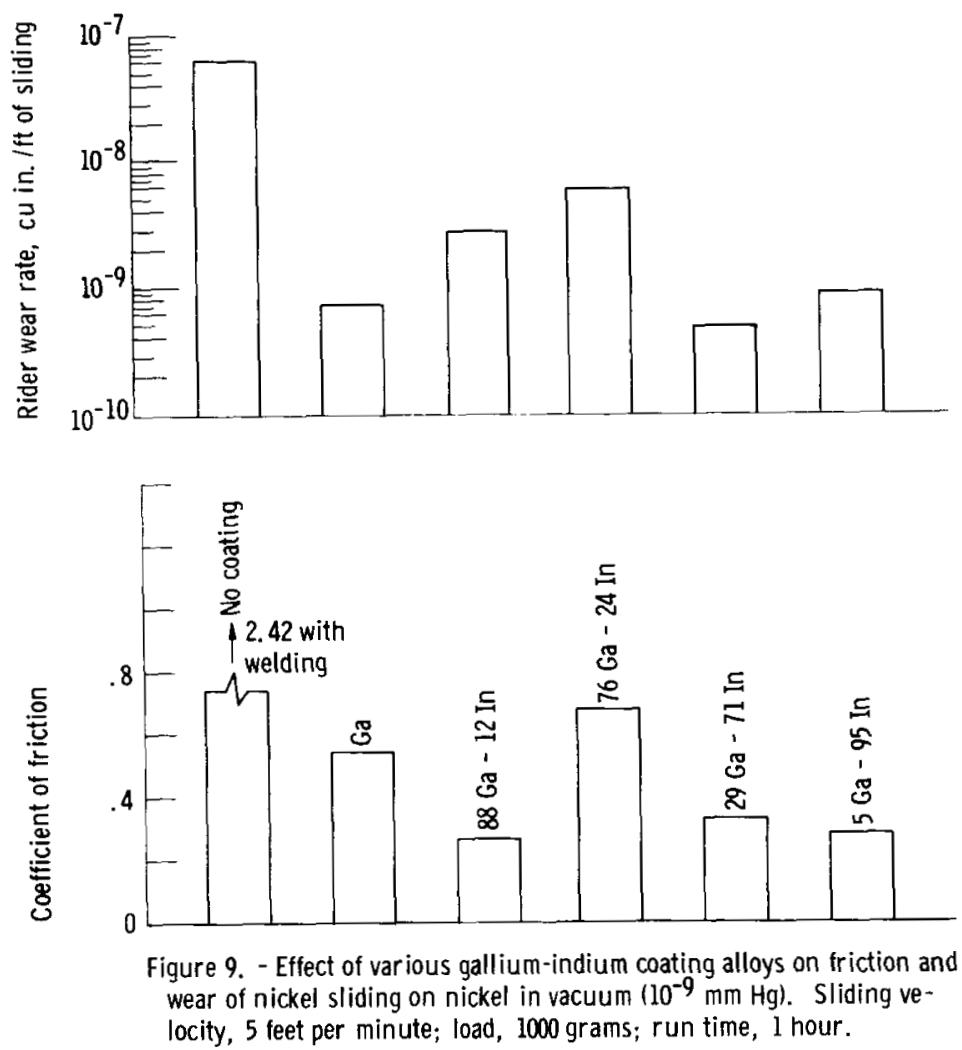

general, the friction of nickel disks with nickel riders was reduced to one-fourth to oneeight that of the uncoated specimens by coating with gallium-indium alloys. The wear was reduced by a factor of at least 10 over the unlubricated metal combination. In this series of experiments, the friction and wear data reflect the melting point of the alloy coating. The highest wear was obtained with the lowest melting alloys. This result again indicates the corrosive nature of the gallium when in liquid form. Evaluating the contribution of the alloying effect is difficult. It is most pronounced where the most gallium is available. Obviously, the friction and wear at the high indium concentration (fig. 9) agree with the results obtained in the earlier slow-speed argon investigation (fig. 4(c), p. 7).

\section{SUMMARY OF RESULTS}

Based on the friction and wear data obtained in argon and in vacuum in this investigation with gallium and gallium alloy coatings (initially approximately $0.001 \mathrm{in}$. thick) on 440-C stainless steel disks with 440-C riders, the following summary remarks can be made:

1. Pure gallium was an effective lubricant at $75^{\circ}$ and $500^{\circ} \mathrm{F}$. At the elevated temperature $\left(500^{\circ} \mathrm{F}\right)$, however, rider wear rate approached that obtained without the lubricating film. 
2. The wear rate of 440-C stainless steel can be reduced by reducing the concentration of gallium in the surface lubricating film. The addition of other soft, low-melting metals (tin, silver, and indium) was effective in reducing wear with gallium films.

3. The most favorable alloy investigated was a ternary alloy ( 20 gallium - 60 indium - 20 tin) that ran in vacuum to 2000 feet per minute at a wear rate that was appreciably less than any other coating examined. This coating exhibited a wear rate one ten-thousandth that of uncoated $440-\mathrm{C}$ when examined under identical conditions.

4. High indium-content coatings effectively reduced friction and wear of nickel disks with nickel riders in vacuum. Friction was reduced to one-fourth to one-eighth, and wear was reduced to one ten-thousandth that of the uncoated nickel disk with nickel rider.

Lewis Research Center,

National Aeronautics and Space Administration, Cleveland, Ohio, December 14, 1964.

\section{REFERENCES}

1. Buckley, D. H.; and Johnson, R. L.: Gallium-Rich Films as Boundary Lubricants in Air and in Vacuum to $10^{-9}$ Millimeters of Mercury. ASLE Trans., vol. 6, no. 1, Jan. 1963, pp. 1-11.

2. Cochran, C. N. ; and Foster, L. M. : Vapor Pressure of Gallium, Stability of Gallium Suboxide Vapor, and Equilibria of Some Reactions Producing Gallium Suboxide Vapor. Jour. Electrochem. Soc., vol. 109, no. 2, Feb. 1962, pp. 144-148.

3. Dushman, Saul: Scientific Foundations of Vacuum Technique. John Wiley \& Sons, Inc., 1962, pp. 691-701.

4. Lyon, R. N., ed.: Liquid-Metals Handbook. NAVEXOS-P-733, AEC, June 1952, pp. 170-171.

5. Peterson, M. B. ; and Johnson, R. L. : PbO and Other Metal Oxides as Solid Lubricants for Temperatures to $1000^{\circ}$ F. Lubrication Eng., vol. 13, no. 4, Apr. 1957, pp. 203-207.

6. Hansen, M. : Constitution of Binary Alloys. Second ed., McGraw-Hill Book Co. , Inc. , 1958. 